\title{
Influence of Parmigiano Reggiano Diet on Male Sexual Behavior in Rats: Behavioral and Neurochemical Study
}

\author{
V. Di Viesti ${ }^{*}, a$, G. Carnevale ${ }^{b}$, M.M. Carrozzo ${ }^{c}$, M. Zavatti ${ }^{b}$ and M. Baraldi ${ }^{d}$
}

Departments of ${ }^{a}$ Biomedical Sciences, University of Modena and Reggio Emilia, via Campi $287 ;{ }^{b}$ Pathological Anatomy and Forensic Medicine, University of Modena and Reggio Emilia, via Del Pozzo 71; ${ }^{c}$ Pharmaceutical Sciences, University of Modena and Reggio Emilia, via Campi 183; ${ }^{d}$ Foundation Mario Baraldi for Sciences, via Rossini 80, 41100 Modena, Italy

\begin{abstract}
The influence of Parmigiano Reggiano (P.R.) cheese on copulatory behavior was studied in male rats. Sexually naïve, sluggish and potent rats were chronically fed with a diet of P.R. cheese for $10 \mathrm{~d}$. Mount, intromission, ejaculation latencies and the percentage of mounting and ejaculating animals were recorded during the mating test. Microdialysis technique was used to detect the extracellular levels of dopamine (DA) and its metabolite dihydroxyphenylacetic acid (DOPAC) in rat brain following the P.R. diet. The P.R. diet was able to improve sexual behavior in naïve rats increasing the percentage of mounting and ejaculating animals. Moreover it was able to reduce latencies of mounts, intromissions and ejaculations and to increase the percentage of mounting and ejaculating animals in sluggish rats. Finally, in the microdialysis study an increase in DA and its metabolite DOPAC was found in P.R. fed naïve rats in comparison with control group.
\end{abstract}

Keywords: Parmigiano Reggiano, male rat, sexual behavior, cerebral microdialysis, dopamine.

\section{INTRODUCTION}

Parmigiano Reggiano (P.R.) is an italian cheese of protected designation origin (PDO). It is a hard, cooked cheese made from raw partly skimmed cow's milk supplemented with natural whey starter [1, 2]. It is produced in specific areas of northern Italy: particularly in the southern lowlands of the Po valley and the northern Apennines. Like the majority of food materials, its chemical composition is a mixture of a large number of ingredients. For P.R. cheese, the details of this composition evolve throughout its maturation [3] or as a function of raw materials and storage environment. Many analyses have been performed to investigate the specific composition of P.R. cheese. The presence of lipids, free amino acids (AA), oligopeptides, several organic acids, fragrances or microbiological constituents has been identified [3]. Among the free AA present in P.R. cheese there is tyrosine (Tyr), a precursor of dopamine (DA). At first L-tyr is converted to L-DOPA by tyrosine hydroxylase enzyme, and, thereafter, L-DOPA is converted to DA by L-aromatic amino acid decarboxylase enzyme [4]. It is well known that sexual behavior is regulated by different neurotransmitters and neuropeptides, among which DA is certainly one of the most extensively studied [5]. It has been repetitively shown to play a facilitatory role on male sexual behavior in mammals [6, 7]. In particular, the administration of apomorphine (a nonselective

\footnotetext{
*Address corresponding to this author at the Department of Biomedical Sciences, Section of Pharmacology, Via Campi 287, I-41100 Modena, Italy; Tel: +39-0592055158; Fax +39-0592055376;

E-mail: vittoria.diviesti@unimore.it
}

D1/D2 receptor agonist) or L-DOPA decreased both intromission and ejaculation latencies in rats $[8,9]$. Indeed, different studies have showed that sexual motivation and copulation in male rats are associated with DA release in the nucleus accumbens (NAc) [9]. This cerebral area is principally innervated by dopaminergic neurons of the ventral tegmental area, and it has been suggested that it play a key role in male sexual behavior. Different studies showed increased DA levels in the NAc during copulatory activity [10]. In particular, microdialysis studies demonstrated that extracellular DA increased when male rats are exposed to inaccessible estrous females, and remains elevated during copulatory behavior until ejaculation [11].

Given these findings, the present study was designed to investigate the influence of chronic ingestion of P.R. cheese on sexual behavior in male rats. In addition, we evaluated the effect of P.R. cheese diet on the level of DA and its metabolite dihydroxyphenylacetic acid (DOPAC) in NAc by means of the microdialysis technique.

\section{MATERIALS AND METHODS}

\section{Animals and Diet}

Sprague-Dawley rats of either sex, weighing from $160 \mathrm{~g}$ (females) to $220 \mathrm{~g}$ (males), were purchased from Charles River Laboratories (Calco, Lecco, Italy). Males were individually housed in single plexiglass cages, while females were housed two per cage: all animals were maintained under controlled laboratory conditions 
$\left(22 \pm 1{ }^{\circ} \mathrm{C}\right.$ and $60 \%$ relative humidity) on a reversed 12 $\mathrm{h}$ light/dark cycle. Female rats were used as stimuli in mating tests. After one week-adaptation period, the females were ovariectomized under ketamine hydrochloride (Ketavet $100^{\circledR}$, Farmaceutici Gellini, Latina, Italy) plus xylazine hydrochloride (Rompun ${ }^{\circledR}$, Bayer AG, Leverkusen, Germany) anesthesia and allowed to recover from the surgery for three week. They were brought into estrous by the administration of a single subcutaneous dose of $10 \mu \mathrm{g}$ estradiol benzoate (Estradiolo AMSA ${ }^{\circledR}$, AMSA, Rome, Italy) $48 \mathrm{~h}$ before the copulatory tests and $500 \mu \mathrm{g}$ progesterone (Prontogest $^{\circledR}$, AMSA, Rome, Italy) $4 \mathrm{~h}$ before the copulatory tests. The females were screened with nonexperimental sexually experienced males and only those exhibiting good sexual receptivity (solicitation behavior and lordosis in response to mounting) and no rejection behavior, were used. Male rats were randomly divided into two groups: one was fed a normal diet with commercial rat pellets (Global Diet 2018, Mucedola s.r.l., Milano, Italy) (25 g/d for $10 \mathrm{~d})$, and the other fed a P.R. (seasoned for 24 months) diet $25 \mathrm{~g} / \mathrm{d}$ for $10 \mathrm{~d}$. Table 1 shows the AA content and the nutritional characteristics of commercial rat pellets and P.R. cheese. Since the energy density of commercial rat pellet and P.R. are respectively $3.1 \mathrm{kcal} / \mathrm{g}$ and 3.9 $\mathrm{kcal} / \mathrm{g}$, the two diets were considered isocalorics. Every morning pre-weighed chow pellets and cheese $(25 \mathrm{~g})$ were introduced into the cage. After each feeding, the remaining food was weighed and the amount ingested was recorded. Between the two experimental groups significant differences in the food consumption were no found. Before the experiment, the group of animals fed a P.R. diet were accustomed to eat only the cheese. Animals had free access to deionized drinking water throughout the study.

Animal care, maintenance and surgery were conducted in accordance with the Italian law (D.L. no. 116/1992) and European legislation (EEC no. 86/609). The experimental design and procedures received the approval of the Bioethical Committee of the Italian National Institute of Health (Ministerial Decree 205/2008-B).

\section{Mating Test}

The sexual behavior of male rats was monitored by trained observers, without knowledge of the experimental design, in a sound-attenuated, air conditioned room lit with a dim red light, during the

Table 1: Nutritional Characteristics of Commercial Rat Pellets and P.R. Cheese

\begin{tabular}{|c|c|c|}
\hline & Commercial rat pellets & P.R. cheese \\
\hline \hline Energy density (kcal/g) & 3.1 & 3.9 \\
\hline AA content (\%): & & 2.3 \\
\hline Asp & 1.4 & 6.0 \\
\hline Glu & 3.4 & 0.9 \\
\hline Ala & 1.1 & 0.7 \\
\hline Gly & 0.8 & 1.1 \\
\hline Thr & 0.7 & 3.6 \\
\hline Pro & 1.6 & 1.9 \\
\hline Ser & 1.1 & 2.9 \\
\hline Leu & 1.8 & 1.3 \\
\hline Ile & 0.8 & 1.4 \\
\hline Val & 0.9 & 1.6 \\
\hline Phe & 1.0 & 1.8 \\
\hline Tyr & 0.6 & 1.0 \\
\hline Met & 0.4 & 0.2 \\
\hline Cys & 0.3 & 2.5 \\
\hline Lys & 0.9 & 0.9 \\
\hline His & 0.4 & 0.8 \\
\hline Arg & 1.0 & 0.3 \\
\hline Trp & 0.2 & \\
\hline & & \\
\hline
\end{tabular}


early portion of the dark cycle. Single male rats were placed in rectangular glass observation cages $(40 \mathrm{~cm} \times$ $50 \mathrm{~cm} \times 40 \mathrm{~cm}$ ) and allowed to become accustomed to the test chamber for $5 \mathrm{~min}$. Then a sexually receptive female rat was introduced into the cage and the mating test started. The following parameters of sexual behavior were measured as previously described by Ågmo [12] and by Zanoli et al. [13, 14]:

(1) mount latency (ML): time from the introduction of the female to the first mount;

(2) intromission latency (IL): time from the introduction of the female to the first intromission (vaginal penetration);

(3) ejaculation latency (EL): time from the first intromission to ejaculation;

(4) post-ejaculatory interval (PEI): time from ejaculation to the first intromission of the second copulatory series.

Tests were normally ended immediately after the first post-ejaculatory intromission; or if intromission did not occur within $15 \mathrm{~min}$; or if ejaculation latency exceeded $30 \mathrm{~min}$; or in the case that post-ejaculatory interval exceeded $15 \mathrm{~min}$. Rats were trained with sexually receptive females in a series of seven preexperimental tests with the aim to classify males as sexually potent or sluggish. We took in account only the results obtained in the last three pre-experimental tests. Rats achieving ejaculation in all the three tests were defined as sexually potent, while those achieving ejaculation in one or two of the last three preexperimental tests were considered sexually sluggish [15]. This group included subjects that displayed mounts or intromissions but did not ejaculated in any of the three pre-experimental tests. Another group of rats was never exposed to sexual experience prior to testing (naïve).

\section{Microdialysis Procedure}

Sexually naïve male Sprague-Dawley rats (Charles River Laboratories, Calco, Lecco, Italy) weighing 250$300 \mathrm{~g}$ were used in the experiments. Each rat was anesthetized with sodium pentobarbital/chloral hydrate mixture $(3.5 \mathrm{ml} / \mathrm{kg}$, i.p.) and stereotaxically implanted with a guide cannula for dialysis probe (CMA 12, Carnegie Medicine, Stockholm, Sweden) in the NAc $(A=+2.0 \mathrm{~mm}, L= \pm 1.0 \mathrm{~mm}, V=-7.9 \mathrm{~mm}$ from the bregma and skull) according to the Brain Atlas of Paxinos and Watson [16]. The guide cannula was fixed to the skull of the rat with two screws and dental acrylic cement. The animals were individually placed in a system for freely moving animals (CMA/120) and allowed to recover from anaesthesia. One day after the surgery the concentric microdialysis probe (CMA 12 Elite $3 \mathrm{~mm}$ membrane active length, Carnegie Medicine, Stockholm, Sweden) was slowly inserted into the NAc via the guide cannula and was perfused with artificial cerebrospinal fluid $\left(\mathrm{NaCl} 147.2 \mathrm{mmol} / \mathrm{l}, \mathrm{CaCl}_{2}\right.$. $2 \mathrm{H}_{2} \mathrm{O} 2.2 \mathrm{mmol} / \mathrm{l}, \mathrm{MgCl}_{2} \cdot 6 \mathrm{H}_{2} \mathrm{O} 1 \mathrm{mmol} / \mathrm{l}, \mathrm{KCl} 4 \mathrm{mmol} / \mathrm{l}$, $\mathrm{Na}_{2} \mathrm{HPO}_{4}$ anydrous $1.4 \mathrm{nmol} / \mathrm{l}, \mathrm{pH} 7.4$ ) at a constant flow rate of $2 \mu \mathrm{l} / \mathrm{min}$ using a CMA microperfusion pump (CMA/100, Carnegie Medicine, Stockholm, Sweden). The samples were stored at $-80{ }^{\circ} \mathrm{C}$ until analyzed for DA and DOPAC as described below. At the end of each experiment, Evans Blue dye was microinjected through the cannula to histologically verify the probe position.

\section{HPLC Determination of Extracellular Levels of Dopamine and its Metabolite DOPAC}

The concentrations of DA and DOPAC in microdialysate samples were analyzed by reversephase HPLC coupled with electrochemical detection. The system consisted of a Shimadzu LC-10AD pump (Shimadzu Italia, Milan, Italy), a Rheodyne 7725 injector (Bensheim, Germany) with loop of $50 \mu \mathrm{l}$ and an ESA Coulchem II EC detector (ESA, Bedford, MA, USA). The electrochemical detector parameters were the following: electrode $1,+0.30 \mathrm{~V}$; electrode $2,-0.30$ $\mathrm{V}$. The mobile phase, consisting of citric acid 50 $\mathrm{mmol} / \mathrm{l}$, sodium octylsulphonate $0.4 \mathrm{nmol} / \mathrm{l}$, Na-EDTA $50 \mu \mathrm{mol} / \mathrm{l}$ and methanol $10 \%$, adjusted to $\mathrm{pH} 2.9$ with 1 $\mathrm{mol} / \mathrm{l}$ potassium hydroxide buffer, was delivered at a flow rate of $1 \mathrm{ml} / \mathrm{min}$ through a Lichrosphere RP-C ${ }_{18}$ column $(4.6 \times 150 \mathrm{~mm}, 5 \mu \mathrm{m})$ (Merck Bracco, Milan, Italy).

\section{Statistical Analysis}

The results of the behavioral experiments, expressed as mean \pm SEM, were obtained by groups of 12 rats each, and analyzed by Student's $t$ test. The percentages of mounting and ejaculating rats in control and treated groups were compared using Fisher's exact test. Student's $t$ test was also used to compare the results obtained in the microdialysis studies. In any case $P<0.05$ was taken as the level of significance. All statistical analyses were performed using GraphPad Prism version 5.0 for Windows (GraphPad Software, San Diego, CA, USA). 


\section{RESULTS}

\section{Effect of Parmigiano Reggiano Diet on Sexual Behavior of Naïve Rats}

The chronic consumption of P.R. increased the percentage of mounting rats from $50 \%$ assessed in control group to $83.3 \%$ observed in rats fed with the cheese. The percentage of ejaculating animals significantly increased from $25 \%$ (control rats) to $83.3 \%$ in the group fed with P.R. $\left({ }^{*} P<0.05\right)$ (Figure 1). No significant change was observed in mount, intromission and ejaculation latencies and in PEI (data not shown).

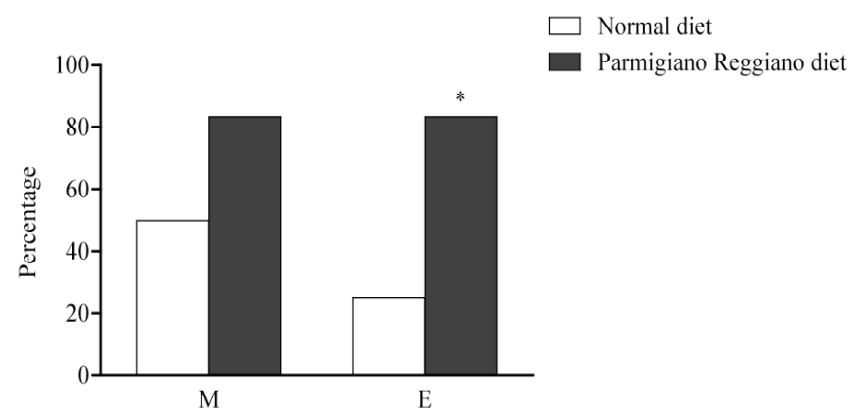

Figure 1: Percentage of mounting $(\mathrm{M})$ and ejaculating $(E)$ animals submitted to P.R. diet in naïve rats in comparison with control ones fed with normal diet. Data are obtained by groups of 12 animals each. ${ }^{*} P<0.05$ compared with vehicletreated group (Fisher's exact test).

\section{Effect of Parmigiano Reggiano Diet on Sexual Behavior of Sluggish Rats}

The effect of P.R. diet on the copulatory behavior of sluggish rats is shown in Figure 2. P.R. diet slightly reduced mount latency in comparison with vehicletreated rats (panel A) while significantly decreasing intromission and ejaculation latencies if compared to the control group $\left({ }^{\star} P<0.05 ;{ }^{* *} P<0.01\right.$, respectively) (panel $\mathbf{B}$ and $\mathbf{C}$ ). In addition, a marked increase in the percentage of mounting and ejaculating rats was observed in P.R. fed rats, but the differences in comparison with control animals were not found statistically significant (Fisher's test). The percentage of mounting animals increased from $33.3 \%$ (control rats) to $75 \%$ in the group fed with the cheese, while the percentage of ejaculating rats increased from $25 \%$ (control rats) to $66.7 \%$ in the group with P.R. diet (panel d).

\section{Effect of Parmigiano Reggiano Diet on Sexual Behavior of Potent Rats}

P.R. diet failed to influence in a statistically significant manner the different parameters recorded during the mating test and the percentage of mounting and ejaculating animals in sexually potent rats, therefore the data were omitted.
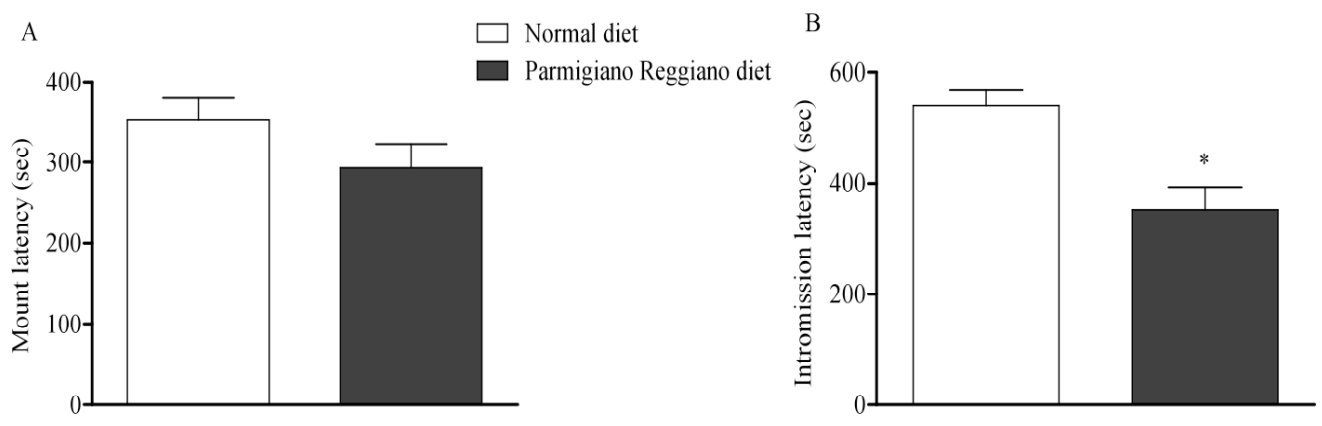

D
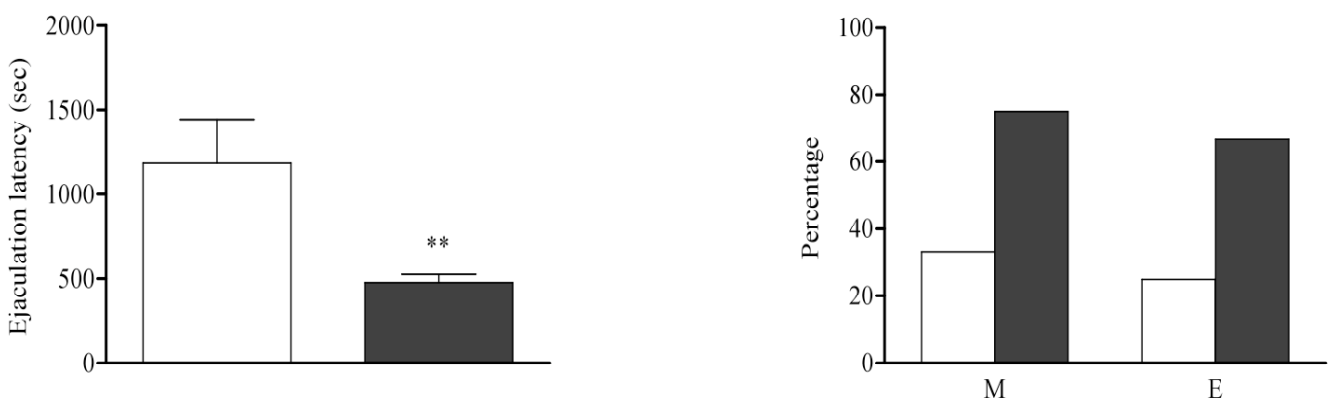

Figure 2: Effect of P.R. on sexual behavior of sluggish rat. Mount latency (panel A), intromission latency (panel B), ejaculation latency (panel $\mathbf{C}$ ) in sluggish rats fed with $P . R$ in comparison with control ones fed with normal diet. Data are mean $\pm S E M, n=$ 12. ${ }^{\star} P<0.05,{ }^{* \star} P<0.01$ compared with normal diet group (Student's $t$ test). Percentage of mounting (M) and ejaculating (E) rats (panel D) in sluggish rats fed with P.R in comparison with control ones fed with normal diet (Fisher's exact test). 

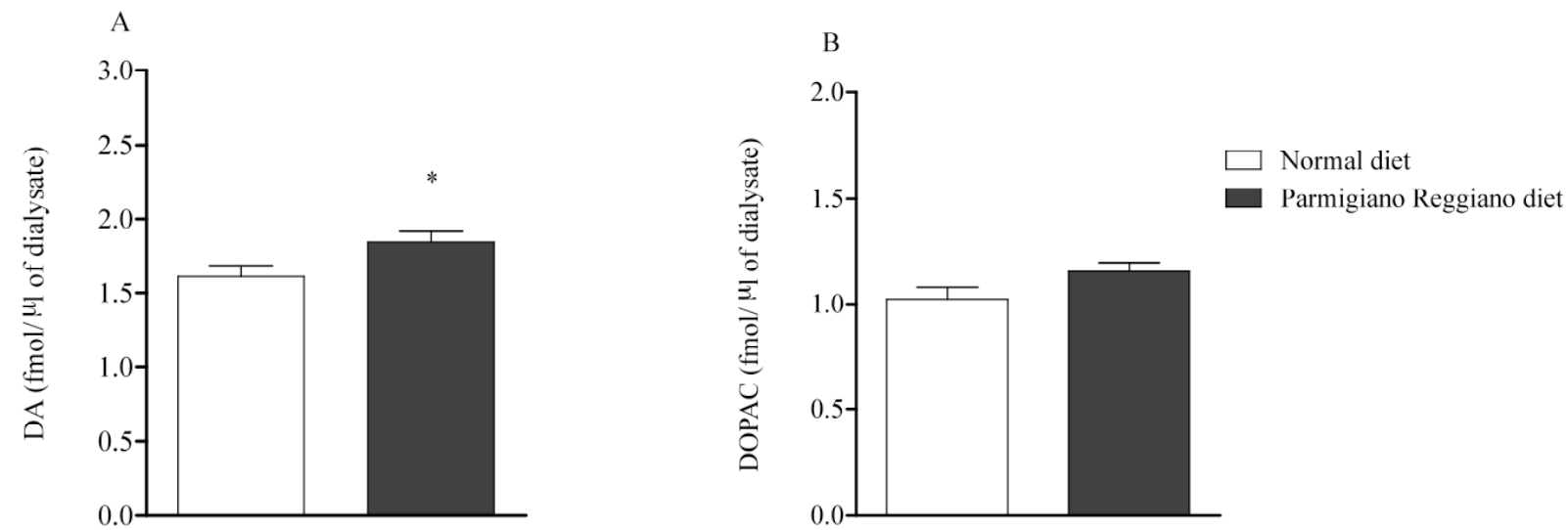

Figure 3: Effect of P.R. diet on basal DA (panel A) and DOPAC (panel B) extracellular levels in dialysates from NAc. Data are mean $\pm \mathrm{SEM}, \mathrm{n}=12 .{ }^{*} P<0.05$ compared with normal diet-treated group (Student's $t$ test).

\section{Microdialysis Studies}

An increase in DA and DOPAC levels was observed in the NAc of rats, $24 \mathrm{~h}$ after the last ingestion of P.R.. In particular, P.R. fed rats showed a significant increase in DA levels in NAc in comparison with control group (normal diet) $\left({ }^{*} P<0.05\right)$ (Figure 3 panel $\left.\mathbf{A}\right)$. On the other hand, DOPAC levels in NAc were found increased in P.R. fed rats, but not in a significant manner in comparison with the control ones (Figure $\mathbf{3}$ panel B).

\section{DISCUSSION}

In the present study we examined the effects of a P.R. diet on sexual behavior of sexually naïve, sluggish and potent rats.

P.R. improved the sexual activity of naïve and sluggish rats in mating tests (but not of potent rats). In particular, the diet was able to increase the percentage of mounting and ejaculating animals; moreover, only in sluggish rats, it was able to reduce mount, intromission and ejaculation latencies. It is well known that P.R. contains a lot of $A A$; some of these represent the precursors of important neurotransmitters. Among the AA present in P.R. cheese in a higher concentration than in commercial rat pellet, there is Tyr, a precursor of the neurotransmitter DA. It has been shown that male copulatory activity is regulated by different neurotransmitters in different brain areas. A large body of evidence implicated the DA in the regulation of male sexual behavior in rats and other mammalian species [17]. In particular, increases in extracellular DA levels in presence of an estrous female, as well as during copulation, have been reported in rats $[18,19]$ and hamsters [20]. Moreover, DA release in sex relevant brain regions before and/or during copulation has been described [21, 22]. Mesolimbic DA is known to play an important facilitatory role in copulation [4, 23] and a number of microdialysis studies reported an increase of DA efflux in NAc associated with both appetitive/motivational and consummatory components of sexual behavior in male rats $[24,25]$. For example, DA released in the medial preoptic area enhances the rate and efficiency of copulation and facilitates genital reflexes; DA released in NAc enhances general responsiveness to motivational stimuli associated with preparatory or appetitive aspects of male sexual behavior [6]. Pharmacological experiments have also demonstrated that drugs, modifying DA levels or DA activity in the central nervous system, have dramatic effects on sexual behavior [26, 27, 28]. DA exerts its effects through a variety of receptor subtypes [4]. It has been demonstrated that the stimulation of D1 receptors enhances same aspects of consummatory male sexual behavior, such as mount attempts and cloacal contact movements, whereas the blockade of D1 receptors by antagonists resulted in a decrease in these measures [4].

Taken together, our data suggest a stimulatory effect of P.R. on rat sexual behavior that can be associated to a stimulatory dopaminergic action in NAc, as a consequence of a higher ingestion of Tyr in P.R. fed animals in comparison with control ones fed with commercial rat pellets.

\section{ACKNOWLEDGEMENTS}

We are grateful to Unigrana S.p.a. (Modena, Italy) for providing P.R. cheese samples used in the present study.

\section{REFERENCES}

[1] Coppola R, Nanni M, lorizzo M, C, et al. Microbiological characteristics of Parmigiano Reggiano cheese during the 
cheese making and the first months of the ripening. Lait 2000; 80: 479-90.

http://dx.doi.org/10.1051/lait:2000139

[2] Bottari B, Santarelli M, Neviani E, Gatti M. Natural whey starter for Parmigiano Reggiano: culture-independent approach. J Appl Microbiol 2010; 108: 1676-84.

http://dx.doi.org/10.1111/j.1365-2672.2009.04564.x

[3] Shintu L, Ziarelli F, Caldarelli S. Is high-resolution magic angle spinning NMR a practical speciation tool for cheese samples? Parmigiano Reggiano as a case study. Mag Reson Chem 2004; 42: 396-401.

http://dx.doi.org/10.1002/mrc.1359

[4] Peeters M, Giuliano. Central neurophysiology and dopaminergic control of ejaculation. Neurosci Biobehav Rev 2008; 32: 438-53. http://dx.doi.org/10.1016/j.neubiorev.2007.07.013

[5] Melis MR, Argiolas A. Dopamine and sexual behavior. Neurosci Biobehav Rev 1995; 19: 19-38. http://dx.doi.org/10.1016/0149-7634(94)00020-2

[6] Blackburn JR, Pfaus JG, Phillips AG. Dopamine functions in appetitive and defensive behaviours. Prog Neurobiol 1992; 39: 247-79.

http://dx.doi.org/10.1016/0301-0082(92)90018-A

[7] Dominguez JM, Hull EM. Dopamine, the medial preoptic area, and male sexual behavior. Physiol Behav 2005; 86: 356-68.

http://dx.doi.org/10.1016/j.physbeh.2005.08.006

[8] Baraldi M, Benassi-Benelli, A. Dissociation of the capacity of apomorphine to evoke penile erection and stereotypy folloeing intragastric administration to adult rats. Farmacol Terap 1975; 361.

[9] Pleim ET, Matochik JA, Barfield RJ, Auerbach SB. Correlation of dopamine release in the nucleus accumbens with masculine sexual behavior in rats. Brain Res 1990; 524: 160-63. http://dx.doi.org/10.1016/0006-8993(90)90507-8

[10] Robinson DL, Philips EMP, Budygin EA, Trafton BJ, Garris PA, Wightman RM. Sub-second changes in accumbal dopamine during sexual behavior in male rats. Neuro Report 2001; 12: 2549-52.

http://dx.doi.org/10.1097/00001756-200108080-00051

[11] Damsma G, Pfaus JG, Wenkstern DG, Phillips AG, Fibiger $\mathrm{HC}$. Sexual behavior increases dopamine transmission in the nucleus accumbens and striatum of male rats: Comparison with novelty and locomotion. Behav Neurosci 1992; 106: 181-91. http://dx.doi.org/10.1037/0735-7044.106.1.181

[12] Ågmo A. Male rat sexual behaviour. Brain Res Brain Res Protoc 1997; 1: 203-209. http://dx.doi.org/10.1016/S1385-299X(96)00036-0

[13] Zanoli P, Benelli A, Rivasi M, Baraldi C, Vezzalini F, Baraldi M. Opposite effect of acute and subchronic treatments with Ferula hermonis on copulatory behavior of male rats. Int $\mathrm{J}$ Imp Res 2003; 15: 450-55. http://dx.doi.org/10.1038/sj.ijir.3901051

[14] Zanoli P, Benelli A, Zavatti M, Rivasi M, Baraldi C, Baraldi M. Improved sexual behavior in male rats treated with a Chinese herbal extract: hormonal and neuronal implications. Asian J Androl 2008; 10: 937-45

http://dx.doi.org/10.1111/j.1745-7262.2008.00437.x
[15] Dewsbury DA. Effect of tetrabenazine on the copulatory behavior in male rats. Eur J Pharmacol 1972; 17: 221-26. http://dx.doi.org/10.1016/0014-2999(72)90162-8

[16] Paxinos G, Watson C. The Rat Brain in Stereotaxic Coordinates. $2^{\text {nd }}$ edn, Academic Press: New York 1986.

[17] Bitran D, Hull EM. Pharmacological analysis of male rat sexual behavior. Neurosci Biobehav Rev 1987; 11: 365-89. http://dx.doi.org/10.1016/S0149-7634(87)80008-8

[18] Hull EM, Du J, Lorrain DS, Matuszewich L. Extracellular dopamine in the medial preoptic area: implications for sexual motivation and hormonal control of copulation. J Neurosci 1995; 15: 7465-71.

[19] Sato $\mathrm{Y}$, Wada $\mathrm{H}$, Horita $\mathrm{H}$, et al. Dopamine release in the medial preoptic area during male copulatory behavior in rats. Brain Res 1995; 692: 66-70. http://dx.doi.org/10.1016/0006-8993(95)00656-B

[20] Triemstra JL, Nagatani S, Wood RI. Chemosensory cues are essential for mating-induced dopamine release in MPOA of male Syrian hamsters. Neuropsychopharmacology 2005; 30: 1436-42.

http://dx.doi.org/10.1038/sj.npp.1300685

[21] Hull EM, Meisel RL, Sachs BD. Male sexual behavior. In: Pfaff DW, Arnold AP, Etgen AM, Fahrbach SE, Rubin RT, editors. Hormones brain and behavior. San Diego, CA: Academic Press 2002; pp. 3-127. http://dx.doi.org/10.1016/B978-012532104-4/50003-2

[22] Melis MR, Succu S, Mascia MS, Cortis L, Argiolas A. Extracellular dopamine increases in the paraventricular nucleus of male rats during sexual activity. Eur J Neurosci 2003; 17 : 1266-72. http://dx.doi.org/10.1046/j.1460-9568.2003.02558.x

[23] Everitt BJ. Sexual motivation: a neural and behavioural analysis of the mechanisms underlying appetitive and copulatory responses of male rats. Neurosci Biobehav Rev 1990; 14: 217-32. http://dx.doi.org/10.1016/S0149-7634(05)80222-2

[24] Mas M, Fumero B, Gonzalez-Mora JL. Voltammetric and microdialysis monitoring of brain monoamine neurotransmitter release during sociosexual interactions. Behav Brain Res 1995; 71: 69-79. http://dx.doi.org/10.1016/0166-4328(95)00043-7

[25] Fiorino DF, Coury A, Phillips AG. Dynamic changes in nucleus accumbens dopamine efflux during the Coolidge effect in male rats. J Neurosci 1997; 17: 4849-55.

[26] Baraldi M, Benassi-Benelli A, Bernabei MT, Cameroni R, Ferrari F, Ferrari P. Apocodeine induced stereotypes and penile erections in rats. Neuropharmacology 1979; 18: 165. http://dx.doi.org/10.1016/0028-3908(79)90057-1

[27] Pfaus JG, Phillips AG. Differential effects of dopamine receptor antagonists on the sexual behavior of male rats. Psychopharmacology 1989; 98: 363-368. http://dx.doi.org/10.1007/BF00451688

[28] Giuliani D, Ottani A, Ferrari F. Influence of sildenafil on copulatory behaviour in sluggish or normal ejaculator male rats: a central dopamine mediated effect? Neuropharmacology 2002; 42: 562-67. http://dx.doi.org/10.1016/S0028-3908(01)00195-2

Received on 17-04-2012

\section{DOI: http://dx.doi.org/10.6000/1927-5951.2012.02.01.11}

(C) 2012 Di Viesti et al.; Licensee Lifescience Global.

This is an open access article licensed under the terms of the Creative Commons Attribution Non-Commercial License (http://creativecommons.org/licenses/by-nc/3.0/) which permits unrestricted, non-commercial use, distribution and reproduction in any medium, provided the work is properly cited. 